\title{
Revolutionary Concepts for Human Outer Planet Exploration (HOPE)
}

\author{
Patrick A. Troutman ${ }^{1}$, Kristen Bethke ${ }^{2}$, Fred Stillwagen ${ }^{1}$, Darrell L. \\ Caldwell, $\mathrm{Jr}^{3}$., Ram Manvi ${ }^{4}$, Chris Strickland ${ }^{5}$, Shawn A. Krizan ${ }^{3}$ \\ ${ }^{\prime}$ NASA Langley Research Center, Hampton, VA 23681 \\ ${ }^{2}$ Princeton University, Dept. of Mechanical and Aerospace Engineering, Princeton, NJ 08544 \\ ${ }^{3}$ Analytical Mechanics Associates, Inc., 17 Research Drive, Hampton, VA 23666 \\ ${ }^{4}$ Jet Propulsion Laboratory, Pasadena, CA 91109 \\ ${ }^{5}$ Swales Aerospace, 1224T1 N. Wright St. Hampton, VA 23681 \\ (757) 864-1954, p.a.troutman@larc.nasa.gov
}

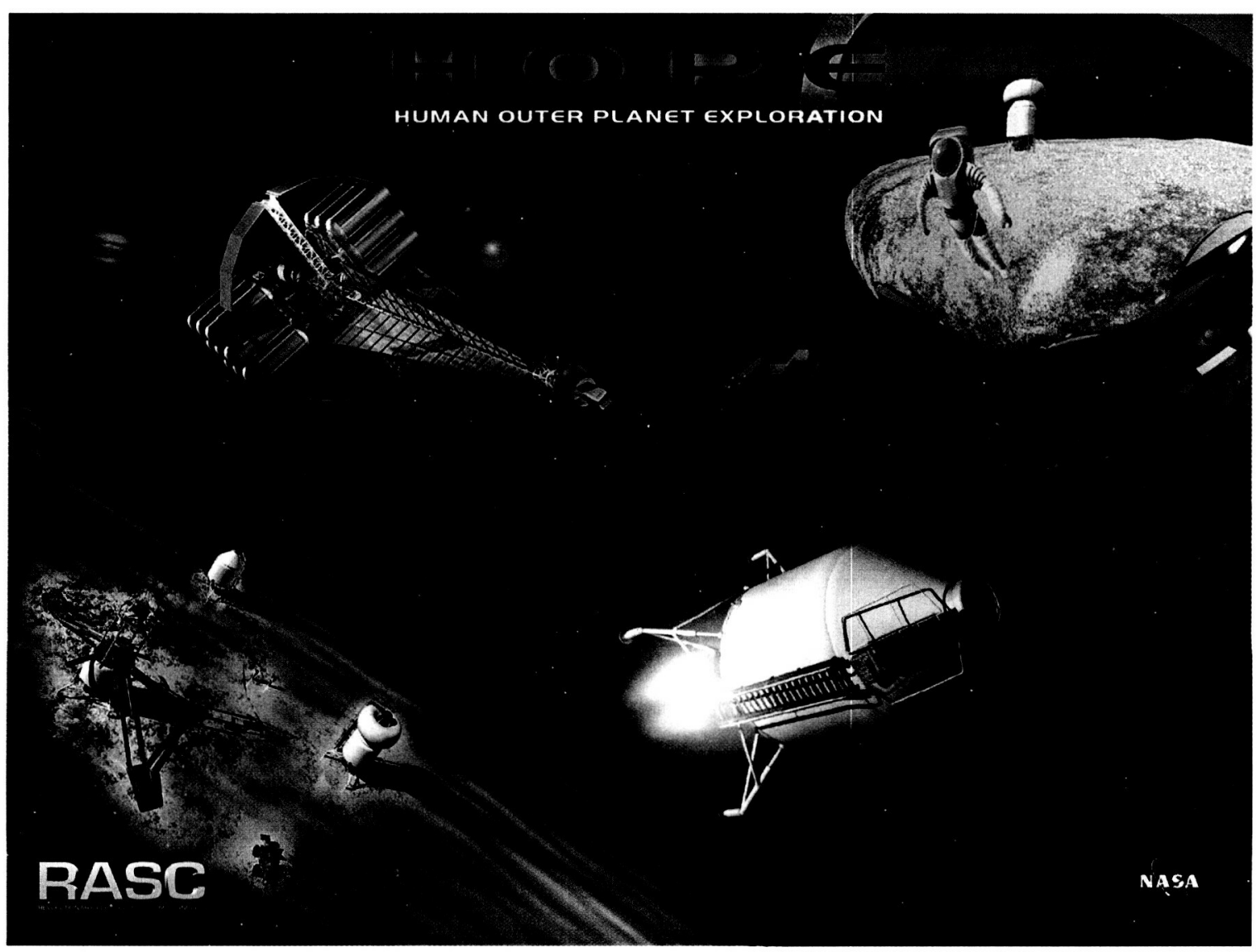

SPACE TECHNOLOGY \& APPLICATIONS INTERNATIONAL FORUM (STAIF - 2003)

"Expanding the Frontiers of Space"

February 2-6, 2003

Albuquerque, New Mexico 


\title{
Revolutionary Concepts for Human Outer Planet Exploration (HOPE)
}

\author{
Patrick A. Troutman ${ }^{1}$, Kristen Bethke ${ }^{2}$, Fred Stillwagen ${ }^{1}$, Darrell L. Caldwell, $\mathrm{Jr}^{3}$., \\ Ram Manvi ${ }^{4}$, Chris Strickland ${ }^{5}$, Shawn A. Krizan ${ }^{3}$ \\ 'NASA Langley Research Center, Hampton, VA 23681 \\ ${ }^{2}$ Princeton University, Dept. of Mechanical and Aerospace Engineering, Princeton, NJ 08544 \\ ${ }^{3}$ Analytical Mechanics Associates, Inc., 17 Research Drive, Hampton, VA 23666 \\ ${ }^{4}$ Jet Propulsion Laboratory, Pasadena, CA 91109 \\ ${ }^{5}$ Swales Aerospace, 1224T1 N. Wright St. Hampton, VA 23681 \\ (757) 864-1954, p.a.troutman@larc.nasa.gov
}

\begin{abstract}
This paper summarizes the content of a NASA-led study performed to identify revolutionary concepts and supporting technologies for Human Outer Planet Exploration (HOPE). Callisto, the fourth of Jupiter's Galilean moons, was chosen as the destination for the HOPE study. Assumptions for the Callisto mission include a launch year of 2045 or later, a spacecraft capable of transporting humans to and from Callisto in less than five years, and a requirement to support three humans on the surface for a minimum of 30 days. Analyses performed in support of HOPE include identification of precursor science and technology demonstration missions and development of vehicle concepts for transporting crew and supplies. A complete surface architecture was developed to provide the human crew with a power system, a propellant production plant, a surface habitat, and supporting robotic systems. An operational concept was defined that provides a surface layout for these architecture components, a list of surface tasks, a 30-day timeline, a daily schedule, and a plan for communication from the surface.
\end{abstract}

\section{INTRODUCTION}

The HOPE study was performed by a multi-center NASA team in support of NASA's Revolutionary Aerospace Systems Concepts (RASC) Program. The RASC Program seeks to develop aerospace systems concepts and technology requirements to enable future NASA missions, which will include crewed journeys to the outer solar system. This RASC work involves identifying new mission approaches and defining the technologies required for the accomplishment of those missions. The HOPE study, in line with the RASC philosophy, has attempted to envision concepts for a human mission to the outer planets and to identify the technology needs for the success of such a mission, which would take place circa 2045.

There have been many studies over the last 20 years that have investigated sending humans to Mars. The significant drivers in these studies relate to the health and safety of the crew. Time away from the safety of Earth needs to be minimized because of exposure to the deep space radiation environment, microgravity effects and the raw amount of consumables (food, water, air) that the crew requires. Minimum energy trajectories from Earth to Mars occur about every two years with a particularly good opportunity in 2018. Most recent NASA studies have focused on the 2018 opportunity thus locking in levels of technology that lead to solutions featuring 100 metric ton class expendable launch vehicles, chemical propulsion and disposable transportation elements. The primary reason for performing the HOPE study is to push us beyond our Mars mission "norms" with respect to architecture and technology in addressing significant drivers of human exploration anywhere in the solar system.

\section{MISSION}

The HOPE team began developing its concept for a crewed mission to the outer planets by envisioning the state of solar system exploration in 2045. The team assumed that by 2045, humans will have landed on Mars and will have established the Earth-Moon L1 Lagrange point as the departure point for human exploration missions. In-Situ 
Resource Utilization (ISRU) of lunar and Mars resources for propellant has become a major enabler of exploration. Automated and reusable systems are also key features of exploration architectures. Also in this timeframe, robotic probes will already have explored Europa and have discovered life-like forms in need of further study.

\section{Destination}

To narrow its focus, the HOPE team chose Callisto as its specific target in the outer solar system. Callisto is an icy and rocky moon of Jupiter, orbiting at a distance of $1,882,700 \mathrm{~km}$, outside of Jupiter's radiation belt. With a diameter of $4820 \mathrm{~km}$ and a mass of $1.076 \times 10^{23} \mathrm{~kg}$, Callisto has $1 / 8$ the gravity of Earth. It is composed of a 55 to 45 mixture ratio of water-ice to rock. Callisto will be desirable as a site for a reusable surface base that supports in-situ production of fuel for further solar system exploration. Callisto is the most heavily cratered place in the solar system with very stable geology that has preserved asteroid impact sites through time. Callisto is just over $5 \mathrm{AU}$ from the sun, which makes it accessible by a range of advanced propulsion technologies. Callisto is also close enough to Europa to teleoperate robots with real time video while avoiding Europa's extreme radiation environment and unstable surface.

\section{Requirements}

The HOPE mission to Callisto was generated based on the following scenario. Earlier robotic probes have identified what appear to be life forms floating in the oceans of Europa and embedded in the ice crust near an asteroid impact site on the surface of Callisto. A crewed expedition is to be sent to the surface of Callisto to teleoperate the Europa submarine and excavate Callisto surface samples near the impact site. The expedition will also establish a reusable surface base with an ISRU plant to support future Jovian system exploration.

As stated earlier, it is assumed there is supporting infrastructure available from which to stage the HOPE mission that was developed primarily for lunar and Mars missions. The distance from the Earth system to Callisto is nearly an order of magnitude greater than the distance to Mars, hence, longer trip times were deemed necessary. In addition to assuming solar system infrastructure circa 2045, the HOPE team established a set of transportation requirements for a crewed mission to Callisto. Any Callisto mission spacecraft system must: 1) leave from the Earth-Moon L1 point, 2) transport six humans to and from Callisto in a maximum of five years, 3) maintain an artificial gravity environment that dips below $1 / 8$ g for no more than one year, 4) deploy a minimum of three crew members to the Callisto surface for a minimum of 30 days, and 5) deploy a surface habitat, crew lander, and in-situ resource utilization (ISRU) plant to the surface all in packages of less than $40,000 \mathrm{~kg}$ each $^{3}$. These requirements allowed the HOPE team to maintain commonality while studying different methods for transportation to Callisto.

\section{Precursor Missions}

Precursor missions can be the backbone of a Callisto scientific program, and, in their development of robotic technologies, can complement future human exploration. The automated missions should be considered as an important part of an integrated Callisto science, technology, and human mission development program. Their dual role is not only desirable, but also essential to ensure that the effort and expense of getting to Callisto yields valuable scientific results and reduces the risk and cost of human exploration. Robotic precursor missions can also establish the degree to which human presence is a requirement for a more efficient and elaborate study of Callisto, and what role automation might be called upon to play in assisting human exploration.

In the first phase, orbiter spacecraft will gather information about Callisto that will be used to determine what landing sites are best for specific crew activities. For optimum mission performance, it will be necessary to pick a landing site based primarily on the ability to achieve HOPE mission objectives. The site must be consistent with operational considerations, such as landing and surface operational safety. Detailed maps of candidate landing sites built from data gathered by precursor robotic missions will define the safety and operational hazards of the sites, as well as confirm whether access to scientifically interesting locations is possible by humans or robotic vehicles. It was determined that the orbiter will require high resolution imaging (including $1 \mathrm{~m} /$ pixel coverage for selected targets and global comprehensive coverage at $50 \mathrm{~m} /$ pixel in stereo); an IR spectrometer with coverage out to 4.5 microns, with high spectral and spatial resolution and high Signal to Noise Ratio (SNR). A laser altimeter and a 
Synthetic Aperture Radar (SAR) with a $25 \mathrm{~m} /$ pixel resolution will also be required. The orbiter will need to be equipped with high volume and high data rate communication capabilities.

To satisfy the human habitation objectives in particular, it would be highly desirable to locate the outpost site where water can be readily extracted from minerals or from surface ice deposits. Such a determination may only be possible from data collected by a robotic surface mission. The second phase, utilizing probes and landers, will perform in-situ science measurements and gather data to assure landing and feasibilities of surface operations on Callisto. A lander (including a mini-rover) capable of determining the mineralogy/chemistry of silicates and organics, and other ices will need to follow the orbiter mission. Observations of geological, physical and mechanical properties of materials around the landing site will require the lander to be equipped with high resolution imaging capabilities. The lander can also be utilized to test some ISRU technologies and measure the radiation environment.

In order to impact the technologies and functionalities associated with the crewed Callisto surface systems, the precursor missions will need to be launched at least 15 years before the crewed missions are to occur. Assuming a 2025 launch date, a bimodal nuclear thermal propulsion system coupled with an orbiter/lander combination could be launched on a Delta IV class launch vehicle from Earth and reach Callisto four years later. The bimodal system would allow $5 \mathrm{~kW}$ of electrical power during the cruise phase and up to $20 \mathrm{~kW}$ or power for surface operations (such as ISRU processing experiments). Results of the mission launched in 2025 could lead to another set of precursors in 2030 that still would provide data that could be utilized to support planning and design of the crewed mission.

\section{INTERPLANETARY VEHICLE CONCEPTS}

The major drivers in any human space exploration architecture revolve around the crew. Time away from Earth increases risk of mission failure due to systems malfunction, crew health problems, and exposure to radiation and microgravity environments. Even with nearly closed air and water loops, the mass of food required to maintain the crew can add up to a significant percent of the total mission payload if trip times are too long. A range of propulsion technologies was investigated to reduce the trip time of the HOPE vehicles along with configuration options to reduce the impacts of microgravity and radiation exposure. Supporting technologies and mission payloads were normalized across the vehicles as much as possible in order to obtain and "apples-to-apples" comparison with respect to different advanced propulsion technologies

\section{Technology Assumptions}

Several classes of propulsion technologies were integrated into different vehicle concepts in support of the Callsito mission ranging from nuclear thermal propulsion which has heritage and testing dating back over 30 years to fusion concepts on the edge of known physics. In between are advanced nuclear electric propulsion options that will require significant technology and engineering advances to become a reality. Supporting technology assumptions in structures, reactor efficiency, radiator efficiency and crew systems can have a significant impact on mission performance that can mask the impacts of varying propulsion system technologies when comparing options. A significant level of effort was focused on the definition and normalization of these supporting technologies. Each concept vehicle configuration results in a craft massing several hundred metric tons. Technologies like syntactic metal foams or advanced composite materials, such as magnesium metal matrix composites, with a strength-toweight ratio of three-to-one over aluminum is assumed to connect the various mission components through a series of truss work and secondary attachment structure. The use of cryogenic tanks for fuel supply and storage is common among the concepts. Fuel tanks are constructed from carbon composite skins with metal reinforcements. The lengths of the large tanks are 16.4 meters and the outer and inner diameters are 5.0 meters and 4.9 meters respectively. The mass of the large tank is 3.9 metric tons. They are sized so that they could be launched from Earth on a large commercial ELV or perhaps be constructed on the moon and delivered to L1 for vehicle assembly. On the megawatt class nuclear electric propulsion concepts, reactor alphas on the order of 3 to $10 \mathrm{~kg} / \mathrm{kW}$ are assumed.

Each vehicle/mission concept carries the same surface infrastructure for use on Callisto. The components of this infrastructure are the surface habitat lander, the ISRU lander, and a reusable crew lander. A surface nuclear power 
supply and automated rovers are included in the ISRU lander mass. The crew lander is used to transport crew and materials between orbit and the surface. While performing surface operations, the crew resides in the surface habitat, a three-person environment that can be reconfigured for six. The ISRU lander produces propellant that can be used for the crew lander from the surface material and relays power to the surface habitat and its scientific experiments. Rovers automatically supply the ISRU lander with surface material for processing, unless they are reassigned for exploration or crew transport. The power supply is a nuclear reactor that connects to the ISRU lander and the surface habitat through a one-kilometer long power cable.
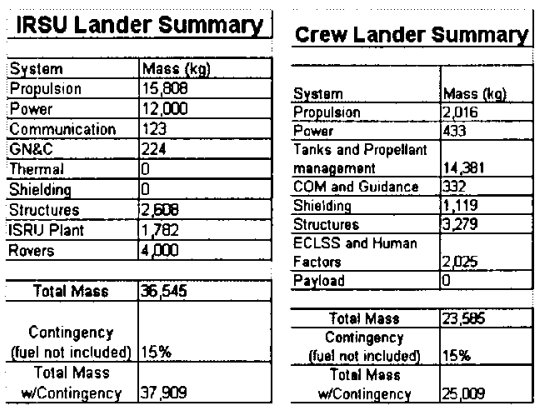

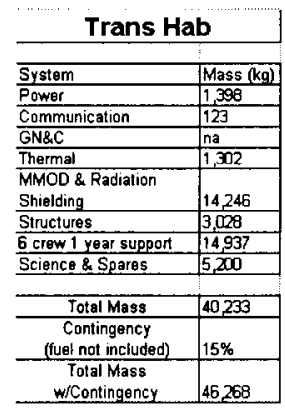

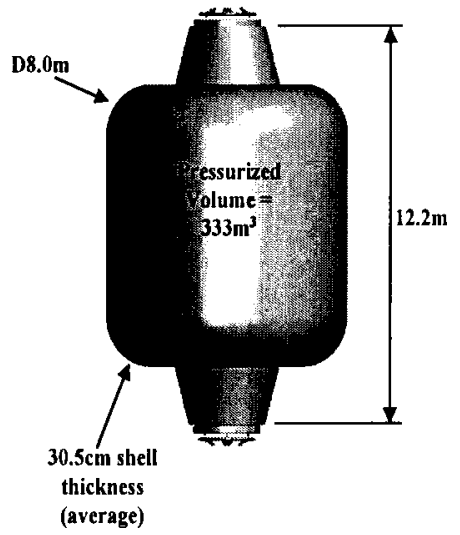

FIGURE 1. Common Elements Carried by All Callsito Mission Vehicles.

The transit habitation (TransHab) module configuration is also the same for each crewed vehicle but the outfitting varies depending on mission length. Also some of the "slower" crewed vehicles utilize two TransHab modules to reduce risk and increase storage for consumables due to longer mission durations. All crewed elements use closedloop, non-organic based filtration and recycling. Wastewater and atmosphere are chemically scrubbed and recycled for crew use every three days. All necessary maintenance supplies and equipment are carried as payload. The average food allotted for each crewmember is 2.75 kilograms per day.

\section{Vehicle Options}

Four mission scenarios utilizing vehicles with a range of propulsion technologies were developed to meet or exceed the minimum Callisto mission objectives. The first option features the highest technology readiness levels (TRLs) for propulsion technology utilized in the HOPE study. The mission profile utilizes separate cargo, tanker and piloted vehicles. Low thrust, nuclear electric propulsion (NEP) cargo and "tanker" vehicles, powered by hydrogen magnetoplasmadynamic (MPD) thrusters, slowly spiral away from L1 on direct transfers to Jupiter and then spiral into Callisto orbit. The NEP vehicles with MW class Brayton cycle fission reactors pre-deploy crew, surface habitation and ISRU landers to Callisto, as well as, $\mathrm{LH}_{2}$ "return propellant" that will be used by the crewed transfer vehicle to return to Earth. The tanker remains in Callisto orbit to be used as an orbital propellant depot once large scale ISRU propellant manufacturing begins on Callisto. After orbiting and surface assets are in position and functioning at Callisto, the piloted Callisto transfer vehicle (PCTV), powered by $3-25 \mathrm{klbf}$ bimodal nuclear thermal rockets (BNTRs), departs L1, performs an Earth perigee burn at $2500 \mathrm{~km}$ altitude for Jupiter and then impulsively captures into Callisto orbit (500 km circular). During its long duration space flight, the BNTR-powered PCTV generates artificial gravity $(\mathrm{ga} \sim 1 \mathrm{gE})$ conditions for its crew via rotation of the vehicle around its center-of-mass. The application of BNTR propulsion for the piloted vehicle greatly simplifies the generation of artificial gravity since there is no need to thrust during the cruise stage, only impulsive burns in the Earth and Jovian systems. The BNTR system also provides all necessary power (greater than $30 \mathrm{~kW}$ ) to sustain the crew during the mission. The piloted mission round trip time is around 4.97 years with 123 days at Callisto. Although all Callisto mission requirements are satisfied, the relatively low specific impulse of the BNTR engines ( $\sim 950$ seconds) contribute to the largest total mission mass of all the options. Another disadvantage is that the PCTV cannot be used again as the crew returns directly to Earth via a small re-entry capsule. 
The second option is nearly identical to the first except that the piloted vehicle utilizes a 10 MW reactor with MPD thrusters instead of BNTR. MPD thrusters offer high specific impulse ( $~ 8000$ seconds) but due to their low thrust must be active through a significant portion of the mission trajectory. Constant thrust coupled with the need to rotate the piloted vehicle to generate artificial gravity lead to complex vehicle geometry and operational requirements. The piloted MPD vehicle rotates about the velocity vector with the MPD thrusters out on booms. The TransHab is balanced by large propellant tanks that together rotate about the vehicle centerline to provide a minimal $1 / 8^{\text {th }} \mathrm{gE}$. Propellant is pumped from smaller tanks surrounding the TransHab to the far end to maintain balance as the propellant is burned. The small hydrogen tanks surrounding the TransHab offer excellent protection to the crew from the deep space radiation environment. However, by the time the crew returns to Earth, the hydrogen has been burned off reducing the effective shielding. About halfway back to Earth, there is not enough propellant to properly ballast the vehicle so it can spin hence the crew must endure microgravity for nearly a year till they arrive at the Earth system. The piloted mission round trip time is almost 4.5 years with 120 days at Callisto. The total mission mass is hundreds of metric tons less then the previous option with the added benefit of a fully reusable piloted vehicle.

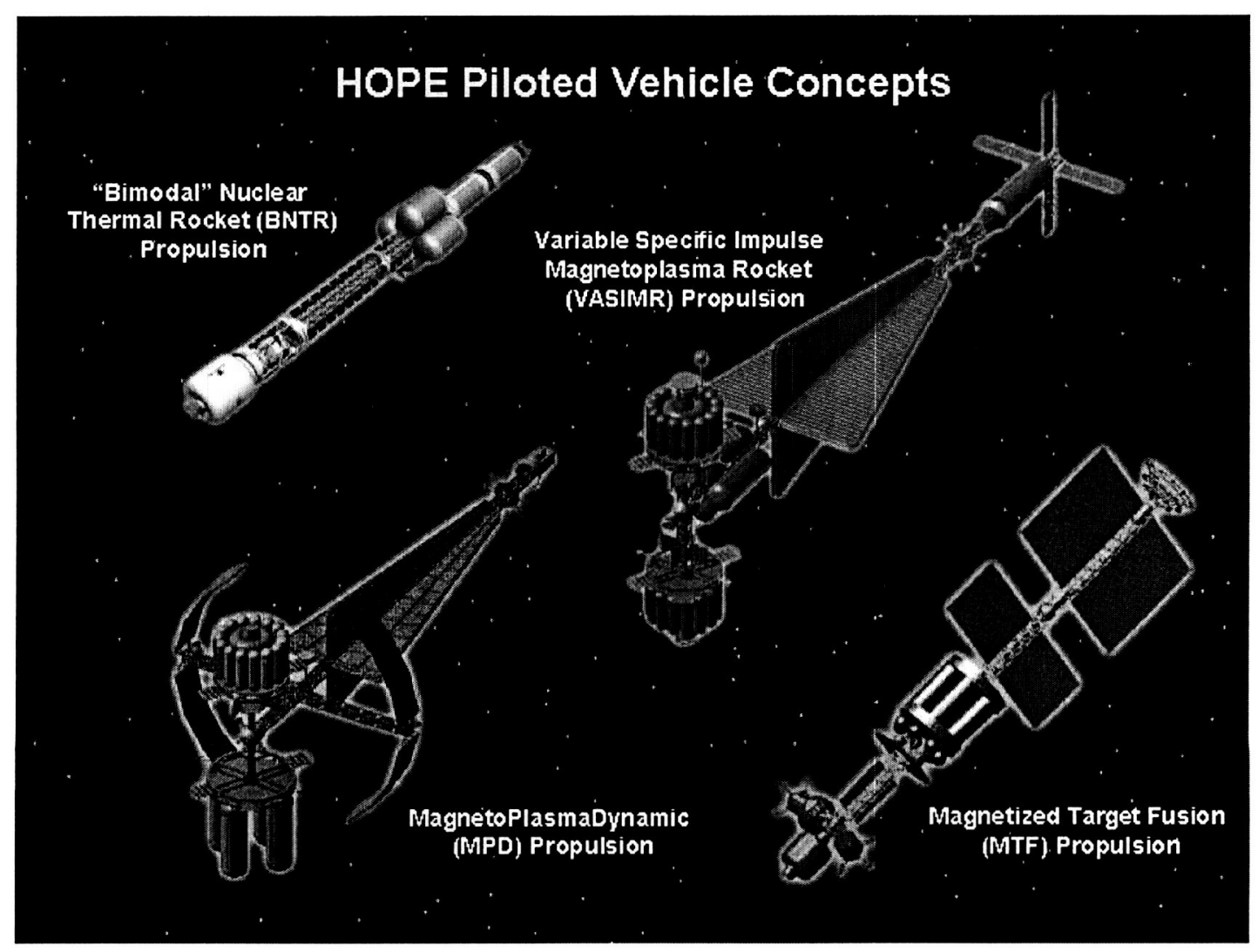

FIGURE 2. HOPE Piloted Vehicle Concepts.

The third option utilizes Variable Specific Impulse Magnetoplasma Rocket (VASIMR) propulsion for all vehicles. VASIMR systems heat hydrogen plasma by RF energy to exhaust velocities up to $300 \mathrm{~km} / \mathrm{s}$ producing low thrust with a specific impulse ranging from 3000 to 30000 seconds. There is significant debate in the advanced propulsion community with respect to the complexity of the engineering challenges associated with the VASIMR system and hence for the purposes of the HOPE study, VASIMR was viewed at a lower state of TRL than MPD thrusters. VASIMR performance potential was utilized in this option to improve upon the previous option. A single VASIMR propelled vehicle is used to transport the surface systems and return propellant to Callisto as opposed to two. As in 
the previous scenarios, the tanker/cargo vehicle remains in orbit around Callisto to be used a future propellant depot. The piloted VASIMR vehicle was fitted with a second TransHab and configured with its main tanks clustered around the rotation axis. The two TransHabs balance each other and are connected by a pressurized tunnel so that the crew can move between them. Like the previous option, there are hydrogen tanks protecting the crew but they do not begin to empty till the last few months of the return mission. The resulting configuration reduces risk by having two crew habitats, the ability to generate artificial gravity throughout the entire mission plus significantly improved radiation protection. The down side is that the payload masses have gone up due to combining the cargo and tanker vehicles and the piloted vehicle enhancements. The $10 \mathrm{MW}$ that was used for the MPD option is not enough power for the VASIMR option to meet mission requirements. The VASIMR option does close assuming 30 MW on each vehicle resulting in a piloted mission round trip time of around 4.9 years with 32 days at Callisto. The total mission mass is between the previous two options with the benefits of increased safety and robustness.

The fourth option features Magnetized Target Fusion (MTF) propelling a single vehicle with all surface systems, payloads and crew for the Callisto mission. MTF is the most aggressive propulsion technology in the HOPE study and offers a potential ISP in the range of 70,000 seconds. The MTF vehicle trajectory features a substantial cruise phase where the engines are not required to fire so the vehicle can rotate end-over-end like the BNTR piloted option to create artificial gravity. The total mission round trip time is just under two years with a 30 day stay on the surface or the same total mission time with a 180 day stay at Callisto for 100 MT more fuel. The significantly shorter trip time coupled with lowest total mission mass is extremely attractive if the technology were to be developed.

\section{SURFACE SYSTEMS AND OPERATIONS}

To identify additional technologies required for a mission to Callisto, the surface phase of the mission was studied. The surface phase is defined by the period of time that the human crewmembers spend on the surface of Callisto. The mission requirements dictate that this phase must support a minimum of three crewmembers for at least 30 days on Callisto. Along with this study of a crewed surface stay, a review of the supporting cargo and deployment requirements was also carried out.

\section{Surface Systems}

On the surface of Callisto, the required $250 \mathrm{~kW}$ of electrical power is supplied by a $1 \mathrm{MW}$ thermal nuclear reactor with a Brayton power converter. With shielding, this reactor has a mass of $10,500 \mathrm{~kg}$. The radiation it produces requires a one-kilometer separation from crewmembers. Transmission cabling connects the reactor/converter system to the ISRU plant and the surface habitat. An important alternative to this massive shielding and long cable is to build up shielding in-situ out of Callisto surface material.

An ISRU plant will be set up on the Callisto surface to convert water into liquid hydrogen and oxygen propellant. The ice that comprises $55 \%$ of Callisto's surface is the source of this water, and it is transferred to the ISRU plant from the surface by robotic systems. To supply the crew lander with the fuel required for a re-supply trip every 30 days, the plant will process $21 \mathrm{~kg}$ of water per hour. It will draw $215 \mathrm{~kW}$ of electrical power.

While on the surface of Callisto, the crew will live and work in an inflatable surface habitat that is transported to the surface prior to the crew's arrival. This surface habitat will provide all of the shelter and consumables that the crew requires for a 30-day stay. The ISRU lander, crew lander and surface habitat all share common propellant tanks and engines used for landing. The tanks in the surface habitat and ISRU plant are used to store cryogenic hydrogen and oxygen processed in by the ISRU plant. The engines in the ISRU plant and surface habitat are used as spares in support of the reusable crew lander.

To give them mobility across the surface of Callisto, the crew will be provided with roving vehicles and robotic aids. Initially, two bulldozer/rovers and three humanoid robots will be deployed on the surface. The bulldozer/rovers will be unpressurized vehicles that function both to acquire surface material and to transport crewmembers across the surface. The total mass of each vehicle will remain under $2000 \mathrm{~kg}$. They will be equipped with a spike to break up the potentially frozen-solid surface, a scoop to gather the surface material, a sensor pod to study the local environment, and two seats to carry crewmembers. Two vehicles will be sent to the surface to provide redundancy 
and so that one can be devoted to crew transport while the other continuously replenishes the ISRU plant with surface material.

The humanoid robots will be multi-functional robots with human dimensions. To limit the crewmembers' exposure to the outside environment, the robots' primary purpose will be to perform science and maintenance tasks that must be completed outside on the surface. Each will have a mass under $200 \mathrm{~kg}$. They will be capable of the full range of human motion and will have the dexterity to perform most sample collection and preparation tasks.

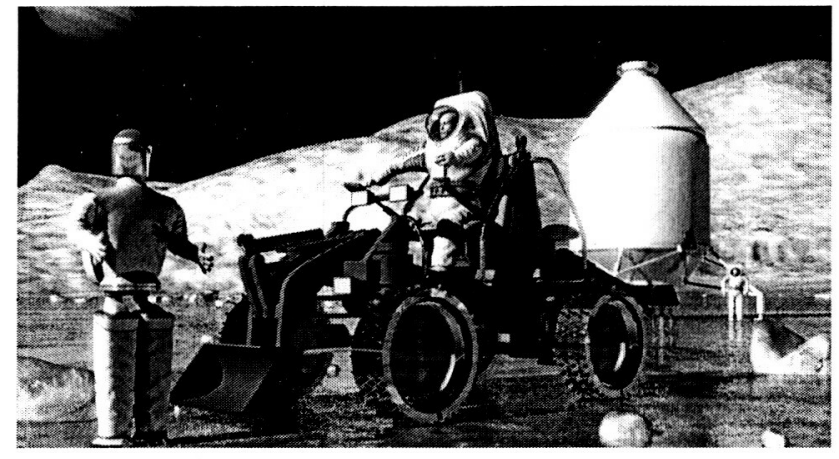

FIGURE 3. Artist Concepts of Humanoid Robot and Bulldozer.

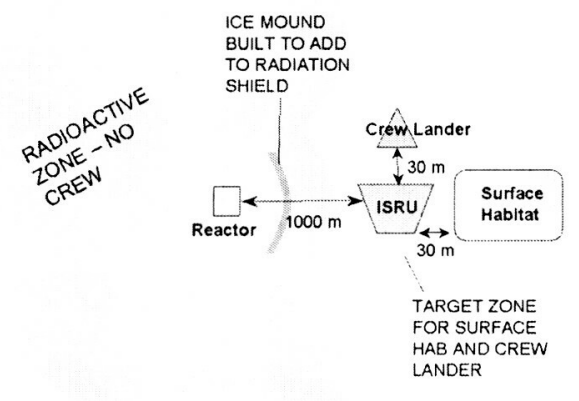

FIGURE 4. Callisto Surface Mission Layout.

\section{Surface Layout}

The surface layout is driven by the necessary one-kilometer separation between the nuclear reactor and the crew, the 30-meter precision landing capability of the lander vehicles, and the desire for close proximity of the crew lander, surface habitat, and ISRU plant. Also, the layout is constrained by the order in which the systems land. In the HOPE Callisto mission scenario that involves a pre-deployed cargo ship, all systems except the crew lander will be pre-deployed to the surface months before the arrival of the crew. The ISRU plant, reactor, and rovers descend together from the cargo ship in one lander vehicle, and the surface habitat descends as a second lander vehicle. After the first vehicle has landed, the reactors will be towed by the bulldozer/rovers away from the ISRU plant, which will remain on top of the lander vehicle. The third and final lander vehicle will be the crew lander, which will descend from the crewed spacecraft when it arrives in Callisto orbit months later. Because of its later arrival, the crew lander's surface destination will depend on the success of the ISRU and surface habitat landers.

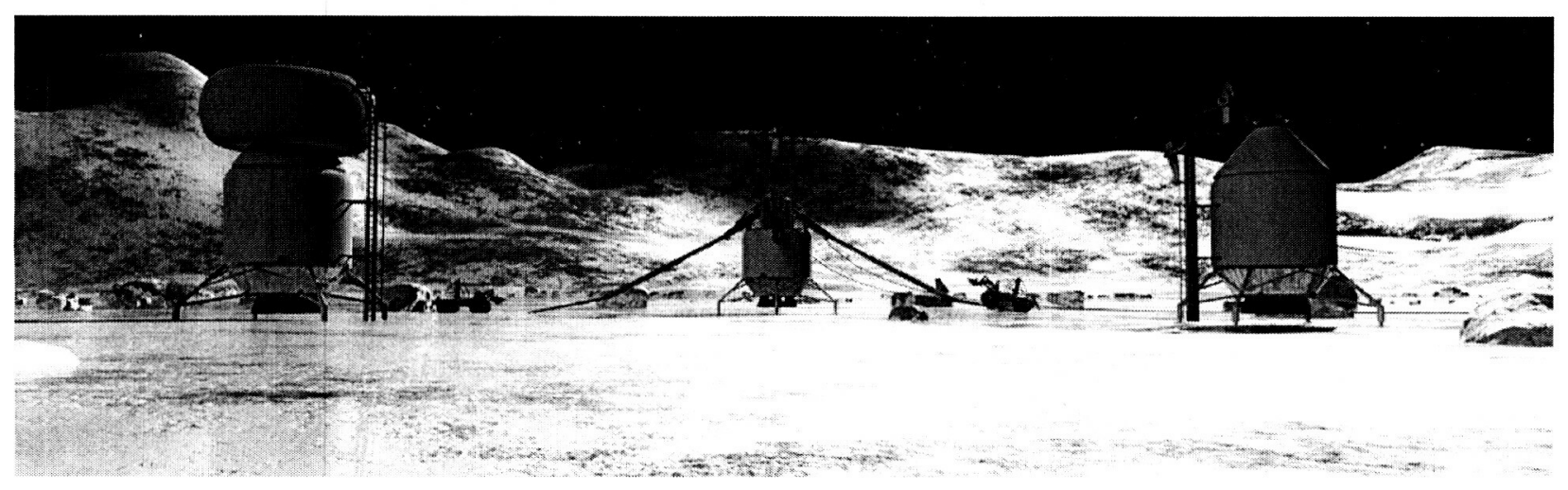

FIGURE 5. Artist Concepts of Surface Habitat, ISRU Lander and Reusable Crew Lander. 


\section{Surface Tasks}

The tasks to be completed on the surface were separated into the categories of set-up, scientific, and maintenance tasks. Set-up tasks are carried out by autonomous systems prior to crew arrival. Scientific tasks are carried out by the crew during their surface stay and by robots both before and during the crew's surface stay. Maintenance tasks are carried out during the crew's stay and after their departure. Detailed task breakdowns and timelines were developed for all surface operations as well as delineating the rolls of humans and robots.

\section{Technology Identification and Development}

This surface scenario depends on several technology advancements. Without the development of these technologies, the surface mission that has been described is not plausible. Table 1 summarizes the technology development requirements for the Callisto surface mission.

TABLE 1. Surface Mission Technology Requirements.

\begin{tabular}{|c|c|c|}
\hline Technology & $\begin{array}{l}\text { Summary Description of Desired } \\
\text { Technology and Key Performance } \\
\text { Metrics }\end{array}$ & $\begin{array}{c}\text { Applications of the Technology } \\
\text { other than HOPE }\end{array}$ \\
\hline Advanced EVA & $\begin{array}{l}\text { Suits with adequate radiation and } \\
\text { thermal protection to enable 3-hour } \\
\text { excursions on Callisto every other day }\end{array}$ & $\begin{array}{l}\text { Lunar and Martian surface } \\
\text { exploration }\end{array}$ \\
\hline Precision Landing & $\begin{array}{l}\text { Ability to reach landing target within } \\
30 \text { meters }\end{array}$ & Lunar and Martian landing \\
\hline Cryogenic Mass Transfer & $\begin{array}{l}\text { Transfer of liquid cryogen over } 30+ \\
\text { meters with less than } 25 \% \text { loss }\end{array}$ & $\begin{array}{l}\text { Liquid cryogen transfer for } \\
\text { spacecraft propulsion }\end{array}$ \\
\hline Super-cold Metals & Support of mechanisms at $100 \mathrm{~K}$ & $\begin{array}{c}\text { Any environment down to } \\
-235 \mathrm{C}\end{array}$ \\
\hline Super-cold composites & $\begin{array}{c}\text { Structural support as well as } \\
\text { flexibility, at } 100 \mathrm{~K} \text {, to enable } \\
\text { inflatable surface habitat design }\end{array}$ & Other super-cold environments \\
\hline Super-cold lubrication & $\begin{array}{l}\text { Prevention of locking of mechanisms } \\
\text { at } 100 \mathrm{~K}\end{array}$ & Other super-cold environments \\
\hline $\begin{array}{c}\text { Brayton Nuclear Reactor } \\
\text { Power System }\end{array}$ & $\begin{array}{l}\text { Delivery of } 250 \mathrm{kWe} \text { power at a mass } \\
\text { of } 12,000 \mathrm{~kg} \text { or less }\end{array}$ & $\begin{array}{l}\text { Advanced propulsion spacecraft, } \\
\text { planetary surface missions }\end{array}$ \\
\hline Mobile Power Plants & $\begin{array}{l}\text { Power to give vehicles and robotic } \\
\text { systems a range of several kilometers }\end{array}$ & $\begin{array}{c}\text { Planetary rovers, interplanetary } \\
\text { spacecraft }\end{array}$ \\
\hline
\end{tabular}

\section{CONCLUSION}

The HOPE study has shown that a crewed mission to Callisto in the 2045 era is possible given advances in life support, propulsion and power generation technologies. Common components, reusable systems, in-situ resource utilization and innovative vehicle design can enable humans to explore a destination that is 8 times as far away as Mars. If some of the technologies and concepts identified in the HOPE mission were to be applied to human exploration of Mars, missions would be measured in months as opposed to years and expeditions could become routine. Most of the technologies identified as enablers for the HOPE mission would not be available to support a 2018 Mars mission: Perhaps the first human mission to Mars should not take place until some of them are.

\section{ACKNOWLEDGMENTS}

The HOPE study was made possible by forward thinkers at the NASA Langley Research Center, NASA Glenn Research Center, NASA Marshall Space Flight Center, NASA Johnson Space Center and the Jet Propulsion Laboratory. 